\title{
Polynomial Distributed Lags and the Estimation of the St. Louis Equation
}

\author{
DALLAS S. BATTEN and DANIEL L. THORNTON
}

\section{T.} SINCE its introduction in 1968 to investigate the relative impact of monetary and fiscal actions on economic activity, the St. Louis equation has been the focus of considerable criticism. ${ }^{1}$ Much of this criticism stemmed from the fact that Andersen and Jordan's conclusions were substantially different from those of the larger econometric models. In particular, they found that changes in the money stock have a significant, lasting impact on nominal income, while changes in high-employment government expenditures and revenues, although having a short-run impact, have no significant, lasting effect.

Criticism of the St. Louis equation generally has fallen into two categories: the specification of the equation and the use of the polynomial distributed lag (PDE) estimation technique, ${ }^{2}$ The second category has

The authors would like to thank $R$. Carter Hill and Thomas $B$. Fomby for their suggestions and comments.

${ }^{1}$ The St. Louis equation first appeared in Leonall C. Andersen and Jery L. Jordan, "Monetary and Fiscal Actions: A Test of Their Relative Importance In Economic Stabilization." this Review November 1968), pp. 11-24.

${ }^{2}$ There have been three major criticisms of the specification of the St. Lotis equation. First since the equation is not derived explicitly from a structural macroeconomic model, relevant exogenous, right-hand-side variables may be excluded, and as a result, the equation may be misspecified. See, for example, Franco Modiglian and Albert Ando, "Impacts of Fiscal Actions on Aggregate Income and the Monetarist Controversy: Theory and Evidence." in Jerome L. Stein, ed., Monetarism, vol. 1, Studies in Monetary Economics (North-Holland, 1976), pp. 17-42, and Robert J. Gordon, "Comments on Modigliani and Ando," in Monetarism, pp. $52-66$.

Second. failure to specify the appropriate indicators of monetary and fiscal actions may distort their exhibited relative importance. See Frank De Leelw and John Kalehbremer, "Monetary and Fiscal Actions: A Test of Their Relative Importance in Economic Stabilization - Comment," this Review (April 1969), pp. 6-11, Edward M. Gramlich, "The Usefulness of Monetary and Fiscal Policy as Discretionary Stabilization Tools," Journal of Money, Credit and Banking (May 1971), pp. 506-32; and E. Gerald Corrigan, "The Measurement and Importance of Fiscal Policy Changes," Federal Reserve Bank of New York Monthly Review (Inne 1970): pp. 133 45 . received far less attention in the literature, and investigations of it have been conducted in a far less systematic manner than investigations of the other category. Consequently, we have undertaken a thorough examination of the use of the PDL estimation technique to determine whether the conclusions of the St. Louis equation are sensitive to either the lag structure employed or the polynomial restrictions imposed.

\section{A BRIET SURVEY OF THE ST. LOUS EQUATION}

The St. Louis equation has not changed substantially since its introduction. The original specification was:

$$
\begin{aligned}
& \text { (1) } \Delta Y_{t}=\alpha+\sum_{i=0}^{3} \beta_{i} \Delta M_{t-i}+\sum_{i=0}^{3} \gamma_{i} \Delta G_{i-i} \\
& +\sum_{i=0}^{3} \delta_{i} \Delta R_{t \ldots i}+\varepsilon_{k}
\end{aligned}
$$

where $\mathrm{Y}=$ nominal $\mathrm{GNP}$,

$$
\begin{aligned}
\mathrm{M}= & \text { a monetary aggregate (either Ml or the mone- } \\
& \text { tary base) } \\
\mathrm{G}= & \text { high-employment federal government expen- } \\
& \text { ditures, }
\end{aligned}
$$

Finally, ordinary least squares (OLS) estimates of the parameters will exbibit simultaneous equation bias if the right-hand-side variables are not exogenous with respect to nominal income. See Stephen M. Goldfeld and Alan S. Blinder, "Some Implications of Endogenous Stabilization Policy," Brookings Papers on Economic. Activity (3: 1972), pp. 585-640; Robert J. Gordon, "Notes on Money, Income, and Cramlich," Journal of Moneu. Credit, and Banking (May 1971), pp. 53345 ; De Leeuw and Kalchbrenner, "Monetary and Fiscal Actions: Comment;" I. W. Elliot, "The Influence of Monetary and Fiscal Actions on Total Spending." Journal of Money, Credit, and Banking (May 1975), pp. 181-92: Keith M. Carlson and Soot E. Mein, "Monetary Aggregates as Monetary Indicators," this Review (November 1980), pp. 12-21; and R. W. Hafer, "The Role of Fiscal Policy in the St. Louis Equation," this Review (January 1982), pp. 17-22. 
$\mathrm{R}=$ highemployment federal govermment revenues and

$\varepsilon=$ error term. ${ }^{3}$

The $\Delta$ s indicate that all variables are first differences (i.e., $\Delta Y_{t}=Y_{t}-Y_{t-1}$ ). The coefficients of each lagged variable were constrained to lie on a fourth degree polynomial with both endpoint coefficients for each variable constrained to equal zero. ${ }^{4}$ In the original article, longer lag lengths were estimated but, since no coefficient past the third lag was statistically signiftcant, these lags were excluded. None of the reported results indicated any investigation of different lag lengths or different polynomial degrees for each variable individually. ${ }^{5}$ In addition, equation 1 also was estimated in a modified form by combining the highemployment government spending and revenue terms into the high-employment surplus/deficit (i.e., R-G).

When Andersen and Carlson made the St. Louis equation the cornerstone of the St. Louis model, it contained the contemporaneous value and four lags of $\Delta \mathrm{M}$ and $\Delta \mathrm{G} ; \Delta \mathrm{R}$, however, was excluded from the equation. ${ }^{6}$ The same degree polynomial was em. ployed, and the endpoint constraints were imposed.

Many studies of the estimation of the St. Louis equation, both critical and supportive, appeared during the 1968-1975 period. These studies investigated, among other things, the sensitivity of the original results to the choice of lag structure and, indirectly, the appropriateness of the restrictions imposed by the use of a PDL model. ${ }^{7}$ Frequently, however, these studies

"Andersen and Jordan, "Monetary and liseal Actions."

${ }^{7}$ Without these constraints, the use of a PDL model would have been erroneous, as each variable in the original equation had only four coefficients in its lag structure while five parameters are needed to eonstruct a fourth degree polynomial the inposition of the endpoint constrants reduces the number of parameters to three. Thus, the ase of a PDL model in the orignal St. Lous equation conserves three degrees of freedom.

sAndersen, in a subseguent paper, did investigate longer lag lengths (agan with the same lag length specified for each variable? using the minimm standard error of the regression as the criterion for choosing the appropriate lag structure. He conclated that, based on the above criterion, the appropriate lag structure was longer than the one chosen orignully, but that the qualitative results were not sensitive to the lag stricture chosen. See Leonall C. Andersen, "An Evaluation of the Impacts of Monetary and Fiscal Policy on Econonic Activity, "Proceedings of the Business and Economic Statistics Section Americal Statsstical Association. 1969), pp. $233-40$.

${ }^{6}$ Leonall C. Andersen and Keith M. Carlson, "A Monetarist Model for Economic Stabilization," this Review (April 1970), pp. 7-25.

"Peter Schmidt and Roger N. Wand, "The Almon Lag Techniane and the Monetary Versus Fiscal Policy Debate," Journal of the American Statistical Association (March 1973), pp. 11-19; Elliott, "The Infuence of Monetary and Fiscal Actions;" Leonall $\mathrm{C}$. made several changes simultaneously (e.g., employing different measures of monetary and/or fiscal policy actions and imposing a different polynomial degree and/or a different lag structure), so that it is difficult to identify the marginal impact of any individual change. Moreover, with one exception, the polynomial restrictions were never examined directly.

Schmidt and waud were the first to investigate the lag lengths for the individual variables of the St. Louis equation. They did so, however, within the framework of a fourth degree polynomial. ${ }^{10}$ They refrained from using endpoint constraints, arguing that the behavior of the polynomial outside of the range defined by the parameters is irrelevant. Using the minimum standard error as their criterion, they determined the appropriate lag structure for the original equation to be six lags of $\Delta \mathrm{M}$, five lags of $\Delta \mathrm{G}$ and seven lags of $\Delta \mathrm{R}$. Despite these changes, their results were not qualitatively different from those of Andersen and Jordan.

Elliott attempted to examine systematically the sensitivity of the results to the choice of lag structure and the impact of the polynomial restrictions. Using a fourth degree PDL procedure, he estimated the equation as modified by Andersen and Carlson with four, eight and twelve lags for each variable. He also employed both ordinary least squares (OLS) and Shiller's method of fitting lags with smoothness priors. His results indicated that the conclusions drawn from the estimation of the St. Louis equation do not depend importantly upon the lag structure chosen or the restrictions imposed by using a fourth degree PDL. Elliott did not conduct statistical tests of these propositions. Instead, he based his conclusions on a casual comparison of the results. Furthermore, he consid-

\footnotetext{
Andersen, "An Evaluation of the Impacts of Monetary and Fiscal Policy on Economic Activity," Corrigan, "The Measurement and Importance of Tiscal Policy Changes;" De Leenw and Kalchbrenner, "Monetary and Fiscal Actions: Comment:" William L. Silber, "The St. Lotis Equation: 'Democratic' and 'Repablican' Versions and Other Experiments," The Review of Economics and Statistics (Novenber 1971), pp. 362-67; Gramlick, "The Usefulness of Monetary and Fiscal Policy;" and Leonall $C$. Andersen and Denis S. Karnosky, "The Appropiate Time Frame for Controlling Monetary Aggregates: The St. Lotis Evidence," in Controlling Monetary Agrerecates 11. The Implementation. Proceedings of a Conference Sponsored by the Federal Reserve Bank of Boston (Series No. 9, 1972), pp. 147-7it

${ }^{8}$ For example, see Corrigan, "The Measurement and Importance of Fiscal Policy Changes;" Silber, "The St. Louis Equation: "Democratic" and "Republican' Versions:" Gramlich, "The Usefinlness of Monetary and Fiscal Policy;" and De Leeuw and Kalchbrenner, "Monetary and Fiscal Actions: Comment."

the one exception is Elliott, "The Influence of Monetary and Fiscal Actions."

${ }^{10}$ Schmidt and Waud, "The Almon Lag Technique."
} 
ered only three possible lag structures (which were assumed to be the same for each distributed lag variable) and only a fourth degree polynomial.

After the Andersen-Carlson modifications of the original Andersen-Jordan equation, the only substantive change in the equation took place as a result of an exchange between Friedman and Carlson in the late $1970 \mathrm{~s} .{ }^{11}$ In updating the sample period over which the equation had been estimated, Friedman noticed that the cumulative effect of government spending became statistically significant. In his response Carlson pointed out that when the original sample was expanded, the standard error of the regression nearly doubled. This indicated that these errors were heteroscedastic. ${ }^{12}$ Using annual rates of change in place of the original first differences of the variables, Carlson respecified the equation. ${ }^{13}$ In this form, the errors were homoscedastic and the cumulative effect of government spending was no longer statistically significant. Since the Friedman-Carlson exchange, the growth rate specification (or an approximately equivalent alternative, first differences in natural logarithms) has been the widely accepted one. ${ }^{14}$

In summary, even though a number of studies have attempted to investigate the effects of the lag length and PDL specification of the St. Louis equation, relatively little work has been directed at investigating

\footnotetext{
${ }^{11}$ Benjamin M. Friedman, "Even the St, Louis Model Now Believes in Fiscal Policy,"Journal of Money, Credit, and Banking (May 1977), pp. 365-67; and Keith M. Cartson, "Does the St. Louis Equation Now Believe in Fiscal Policy?" this Review (February 1978), pp. 13-19.

${ }^{12}$ When the variance-covariance matrix is misspecified, the estimated $t$-ratios are biased, and neither the direction nor extent of the bias can be determined a priori. See G. S. Watson, "Serial Correlation in Regression Analysis. I," Biometrika (December 1955), pp. $327-41$.

${ }^{13}$ This re-specification was proffered as an alternative to first differ ences in the original Andersen-Jordan article. John Vrooman, "Does the St. Louis Equation Even Believe in Itself?" Journal of Money, Credit, and Banking (February 1979), pp. 111-17, attempts to eorrect for heteroscedasticity in the first difference specification. He does so by dividing the observation matrix by the square-root of $\Delta \mathrm{Y}_{\mathrm{t}}$. This transformation, however, creates correlation between the error term and the right-hand-side variables - a violation of one of the dassical assumptions of ordinary least squares estimation.

${ }^{14}$ See, for example, Keith M. Carlson, "Money, Inflation, and Economic Growth: Some Updated Reduced Form Results and Their Implications," this Review (April 1980), pp. 13-19; Carlson and Hein, "Monetary Aggregates as Monetary Indicators"' John A. Tatom, "Energy Prices and Short-Run Economic Performance," this Revicw (Jannary 1981), pp. 3-17; Laurence H. Mever and Chris Varvares, "A Comparison of the St. Louis Model and Two Variations: Predictive Performance and Policy Implications," this Review (Decembes 1981), pp. 13-25; and Hafer, "The Role of Fiscal Policy in the St. Louis Equation."
}

and testing the propriety of the polynomial constraints or the lag structure employed. Furthermore, most previous investigations have been conducted using the first difference specification of the equation. Thus, whether the policy conclusions drawn from the estima tion of the equation (especially for the growth rate specification) are influenced significantly by the choice of lag length and polynomial restrictions employed remains unresolved.

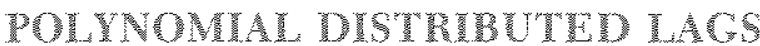

The PDL estimation technique forces the coefficients of each lagged variable of an equation to lie on a polynomial of degree $\mathrm{p}$. In the presence of a high degree of multicollinearity, OLS estimates are not precise. Thus, the rationale for the use of the PDL technique is that it increases the precision of the estimates. Estimates of the individual lag weights, however, will be biased generally unless the correct lag length and degree of polynomial are specified. ${ }^{15}$ Therefore, it is important that the appropriate specification be determined.

There are a number of procedures and criteria for determining the appropriate lag length and polynomial degree. ${ }^{16}$ We use a computationally efficient procedure outlined recently by Pagano and Hartley (hereafter PH). ${ }^{17}$ Details of the PH technique and other relevant considerations are presented in the appendix.

When Almon first introduced PDL models, she suggested that endpoint constraints always be employed.

\footnotetext{
${ }^{15}$ Let $e, p$ and $Q^{*}, \mathrm{p}^{*}$ denote the assumed and correct lag length and degree of polynomial, respectively. Estimates of the parameter vector will be biased if $(a) \ell=\ell^{*}$ and $p<p^{*}$, (b) $\ell<\ell^{*}$ and $p=p^{*}$ or $(c) \ell>\ell^{*}, p=p^{*}$ and $\ell-p^{*}>p^{*}$. In the instance where $\ell-\ell^{*} \leq \mathrm{p}^{*}$, the polynomial distributed lag estimates may be biased, but need not be. That is, there are restrictions that may or may not be satisfied by the data. Furthermore, PDL estimators will be inefficient if $\ell=q^{*}$ and $p>p^{*}$. See $P$. K. Trivedi and $A$. R. Pagan, "Polynomal Distributed Lags: A Unified Treatment," Economic Siudies Quarterly (Aptil 1979), pp. 37-49.

${ }^{16}$ See Trivedi and Pagan, "Polynomial Distributed Lags: A Unified Treatment:" D. F. Hendry and A. R. Pagan, "Distributed Lags: A Survey of Some Recent Developments," umpublished mantscript: Robert J. Shiller, "A Distributed Lag Estimator Derived from Smoothess Priors," Econometrica (July 1973), pp. 775-88; f. D. Sargan, "The Consumer Price Equation in the Post War British Economy: An Exercise in Equation Specification Testing." The Review of Economic Studies (January 1980), pp. 113-35; and George G. Judge and others, The Theory and Practice of Econometrics (John Wiley and Sons, Inc, 1980), chap. 11.

${ }^{17}$ See Marcello Pagano and Michael 1. Hartley, "On Fitting Distributed Lag Models Subject to Polynomial Restrictions," Journal of Econometrics (June 1981), pp. 171-98.
} 
The suggested endpoint constraints take the form

$$
\beta_{\ell+1}=\beta_{\ldots 1}=0,
$$

where $\ell$ is the chosen lag length. Although the endpoint constraints put explicit restrictions on the distributed lag weights outside of their relevant range, they also imply homogeneous restrictions on the lag weights inside the range via homogeneous restrictions on the polynomial coefficients. ${ }^{18}$ Thus, the endpoint constraints add two additional homogeneous restrictions for each PDL variable to those already implied by the PDL model. The problem is that endpoint constraints have no basis in either economic or econometric theory, as Schmidt and Waud have pointed out. ${ }^{19}$ As a result, they represent a set of ad hoc restrictions whose sole purpose is to increase the efficiency of estimation. Nevertheless, their validity can be tested.

\section{APLLICATON TO TUE ST, LOUMS EOUTTON}

To investigate the appropriate lag lengths and polynomial degrees for the St. Louis equation, we employ the growth rate specification ${ }^{20}$

$$
\dot{\mathrm{Y}}_{\mathrm{t}}=\alpha+\sum_{\mathrm{i}=0}^{\mathrm{J}} \beta_{\mathrm{i}} \dot{\mathrm{M}}_{\mathrm{t}-\mathrm{i}}+\sum_{\mathrm{i}=0}^{\mathrm{K}} \gamma_{\mathrm{i}} \dot{\mathrm{G}}_{\mathrm{t}-\mathrm{i}}+\varepsilon_{\mathrm{t}} .
$$

The dots over each variable represent quarter-toquarter annualized rates of change, and $\mathrm{Y}, \mathrm{M}$ and $\mathrm{G}$ represent nominal GNP, money (the M1 definition) and high-employment government expenditures, respectively. The estimation period considered is II/ 1962 to IIU/1982.

\section{Lag Lengh Soloction}

The first step of the PH technique is to select

\footnotetext{
${ }^{18}$ This can be seen by noting that the endpoint constraints require

$$
\delta_{0}+\delta_{1}(-1)+\delta_{2}(-1)^{2}+\ldots+\delta_{1}(-1)^{p}=0 \text { and }
$$$$
\delta_{t}+\delta_{\ell}(\ell+1)+\delta_{2}(\ell+1)^{2}+\ldots+\delta_{1}(\ell+1)=0 \text {. }
$$

These restrictions can be written as $\mathrm{R} \delta=0$, becalise for a $\mathrm{PDI}$ model, $\mathrm{\beta}=\mathrm{H} \delta$, so that $\delta=\mathrm{H}^{+} \beta$, where $\mathrm{H}^{*}=\left(\mathrm{H}^{\prime} \mathrm{H}^{-\mathrm{t}} \mathrm{H}^{\prime}\right.$. Therefore, $R \delta \delta^{-} \mathrm{RH}^{+} \beta^{-}=\mathrm{R}^{+} \beta=0$. Thus, the endpoint constraints impose a set of homogeneous restrictions $R^{*}$ on $\beta$. See Daniel L. Thornton and Dallas S. Batten, "Endpoint Constraints and the St. Louis Equation: A Clarification, "Federal Reserve Bank of St. Louis Research Paper No. 83-001 (1983).

"See Schnidt and Waud, "The Amon Lag Technique," p. 12.

"We chose to employ this specification because it is the one inclıded in the St. Louis model. For a complete specification of the St. Loutis model, see the appendix to Keith M. Carlson, "A Monetary Analysis of the Administration's Budget and Rconomic Projections," this Review (May 1982), pp. 3-14. appropriate lag lengths $(\mathrm{J}, \mathrm{K})$ for money and government expenditure growth. Once these lag lengths are selected, a re-application of the technique results in the selection of the polynomial degrees. ${ }^{21}$ The $\mathrm{PH}$ procedure is somewhat complicated when appropriate lag lengths and polynomial degrees must be selected for two variables. ${ }^{22}$

The use of the PH technique, like other procedures for specifying a distributed lag model, requires the choice of a maximum lag length (L). We considered two choices of L: 12 and $16 .^{23}$

An application of the PH technqiue to the St. Louis equation results in a choice of 10 lags on $\dot{M}$ and 9 on $\dot{G}$. This selection is basically consistent with the results of a standard F-test. ${ }^{24}$ Ordinary least squares estimates of this lag specification, as well as the usual specification with four lags on both $\dot{M}$ and $\dot{G}$, are presented in table 1. Note that the standard error of the regression is reduced substantially and the adjusted $R^{2}$ is increased substantially by including the additional distributed lag variables. Furthermore, the coefficients on the longest lag terms are significant in the longer lag specification. These results suggest that this specification is preferable. Indeed, a likelihood ratio test of the restrictions implied by the current specification rejects them at the 5 percent level. ${ }^{25}$

Nevertheless, it is interesting to note that the conclusions about the long-run efficacy of monetary and fiscal policy are unaffected by the choice of lag structure. The hypothesis of the long-run ineffectiveness of money can be rejected for both lag specifications; the

\footnotetext{
${ }^{21}$ Standard statistical procedures cannot be used to select the lag length if the polynomial degree is specified first. See footnote 6 of the appendix for further details.

${ }^{22}$ The choice of lag length and polynomial degree also involves sequential hypothesis testing. As we note in the appendix, care must be taken in conducting sequential tests. Given the problems with sequential tests (and those of preliminary test estimation), we initially chose a relatively low significance level of 15 percent, opting to guard against incorrectly exduding relevant components of the distributed lag. As a general rule, one would have expected the chosen lag length to be shorter had we used a more common significance level, such as 5 percent. In our tase, the lag specification would have been the same had we selected a 5 percent significance level.

${ }^{23}$ The results for $\mathrm{L}=16$ were identical to those for $\mathrm{L}=12$. Thus, the PI technique seems to be relatively insensitive to the choice of $\mathrm{L}$.

2. With $L=12$ for both $\dot{M}$ and $\dot{\mathrm{C}}$, the $F$-statistic calculated to test the hypothesis that the 10 th lag on $\dot{\mathrm{M}}$ is significant was $2.45^{*}$. The F-statistic calculated for the same test for the 8 th and 9 th lags on $G$ were $2.55^{*}$ and 1.77 , respectively. (The * indicates significance at the 10 percent level.)

${ }^{25}$ The likelihood ratio statistic was 32.13 , which compares with a critical value of $x^{2}(11)$ of 19.68 at the 5 percent level.
} 


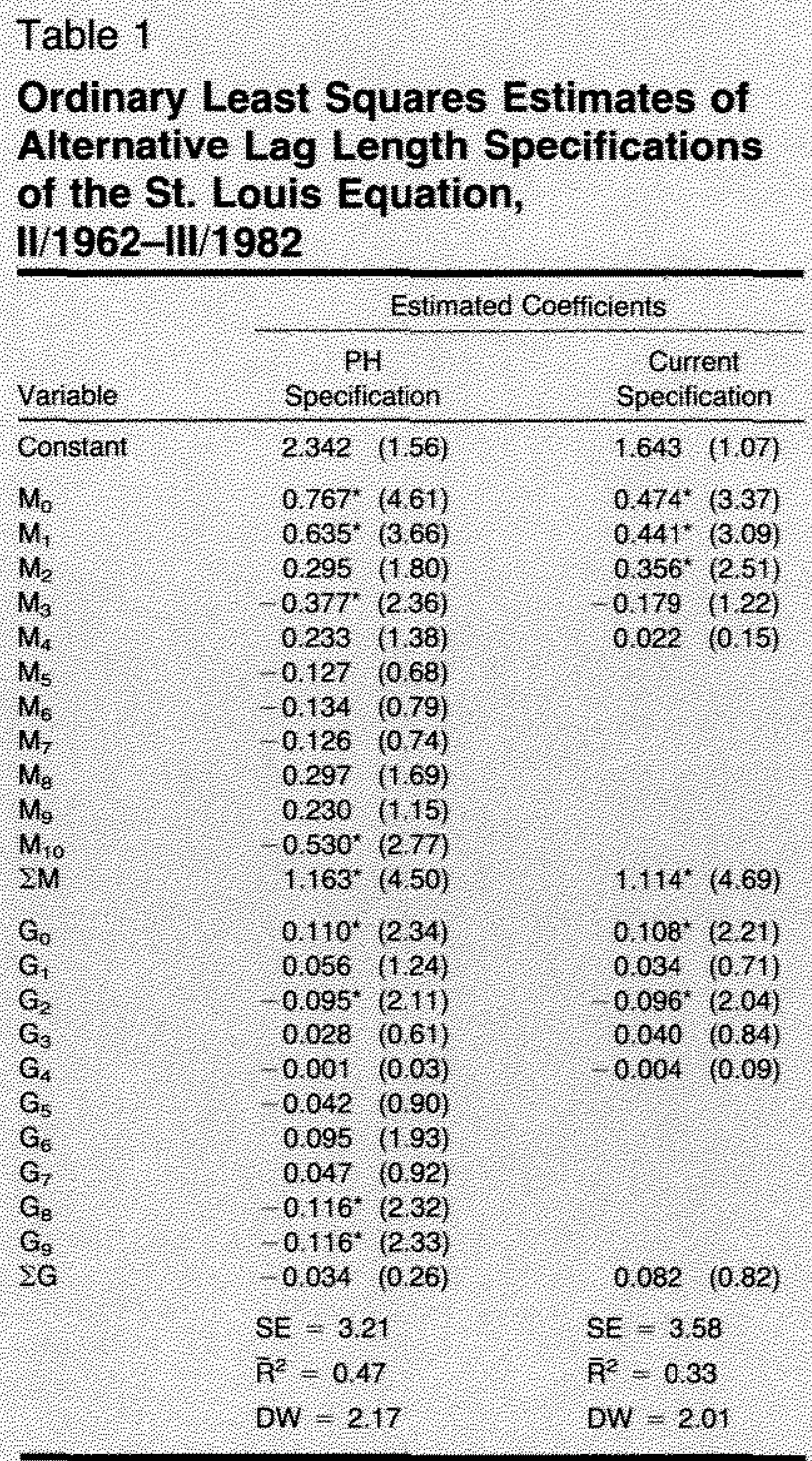

Thdicales significance at the 5 percent level. Absolute value of istatistics in parentreses.

same hypothesis about government expenditures can not be rejected.

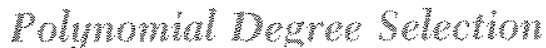

The chosen lag structure is used in the selection of the appropriate polynomial degree. The appropriate polynomial degree is selected by re-parameterizing the model and applying the same technique used to select the lag length.

A direct application of the PH technique to the question of polynomial degree selection results in selecting a ninth degree polynomial on $\dot{\mathrm{M}}$ and a seventh degree polynomial on $\dot{G}$. The results of conventional $F$-tests, however, indicate that there are more restrictive specifications that cannot be rejected at the 5 percent level. Given that the polynomial restrictions tends to smooth out the distributed lag weights and, thus, might result in more accurate out-of-sample foreeasts, we decided to present the results of both the PDL specification resulting from a strict application of the $\mathrm{PH}$ technique and the one determined by employing the greatest number of polynomial constraints that satisfy a conventional F-test at the 5 percent level. The latter specification has a sixth degree polynomial on $\dot{M}$ and a third degree polynomial on $\dot{G}$. The results of the estimation of these specifications (denoted $A$ and $B$, respectively) and the PDL specification presently used (denoted C) are given in table 2 . These equations were estimated with restricted least squares (RLS). ${ }^{26}$ We believe RLS is preferable to the standard PDL method because it makes the parameter restrictions explicit and permits ease in testing the individual and joint PDL restrictions.

It is clear from these results that each of the two longer lag PDL specifications performs better than the current one. Each has a smaller standard error and a larger adjusted $\mathbf{R}^{2}$. Nevertheless, it is interesting to note that the tests of the long-run efficacy of the monetary and fiscal policy variables also are insensitive to the PDL specification. The long-run effect of money is not significantly different from one, while the long-run effect of government expenditures is not significantly different from zero, for all three specifications. ${ }^{2 \bar{i}}$ The short-run distributed lag response patterns, however, differ significantly.

\section{Tests of the Endpoint Constrame}

As we noted earlier, endpoint constraints represent ad hoc restrictions and, thus, should not be employed routinely. Nevertheless, since the current specification of the St. Louis equation employs polynomial restrictions only in the form of endpoint constraints, we decided to test these constraints for all three specifications. The results of these tests for the relevant joint and individual restrictions are presented in table

\footnotetext{
${ }^{26}$ For a discussion of the equivalence between standard PDI estimation and RLS, see Judge and others, The Theory and Practice of Econometrics, pp. 640 42.

${ }^{2}$ Estimates of two other PDL specifications yielded the sane conclusions regarding the efficacy of monetary and fiscal policy. See the appendix for details of these specifications.
} 


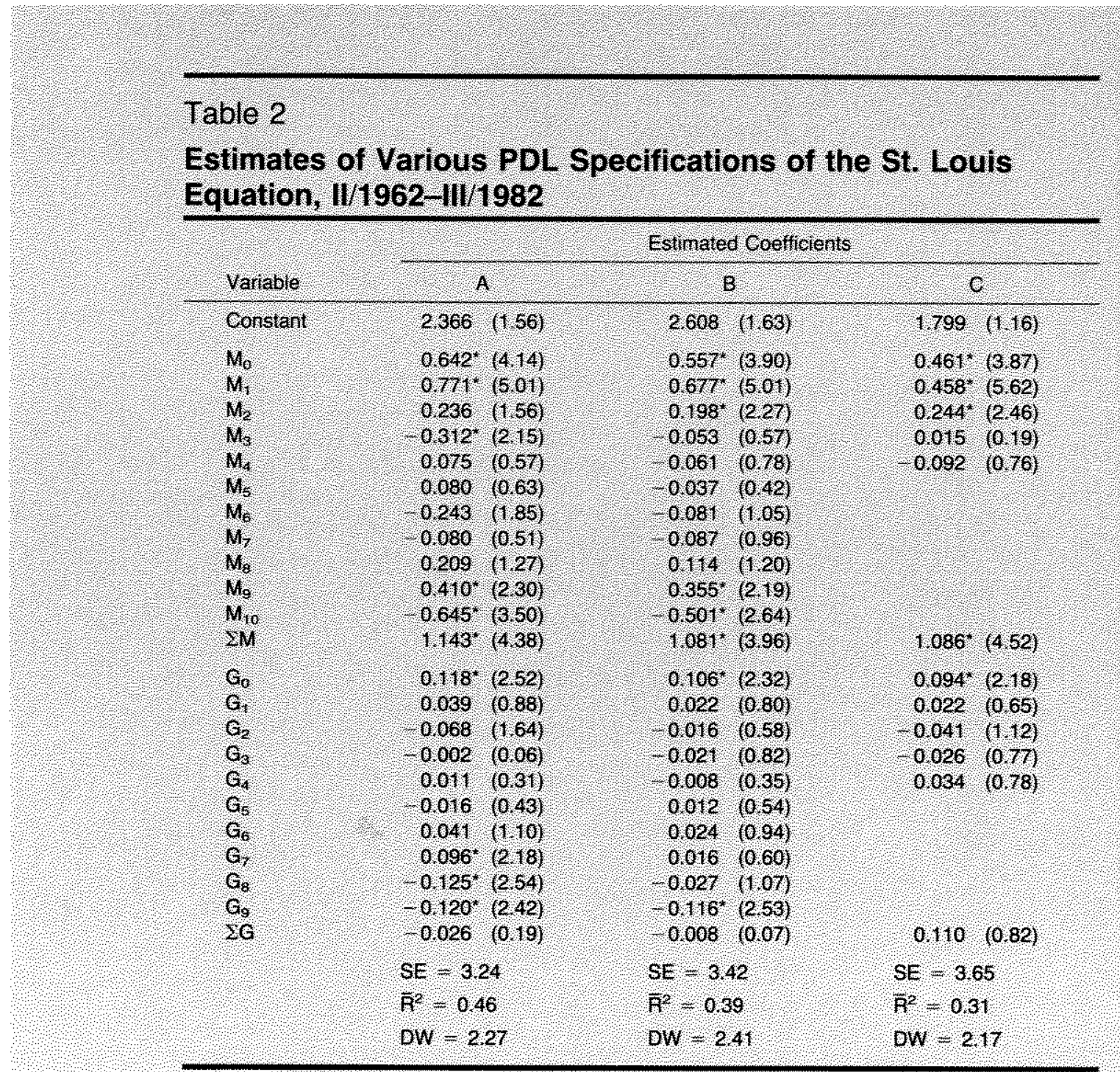

\begin{abstract}
thaicates significance at the 5 percent level. Absolute value of 1 statistics th parentheses, Specitication A has ninth degree and seventh degree polynomals on $\mathrm{M}$ and G, respectively Specilcation B tas sixh and third degree polynomials on M and $G$, respectively, Specification $C$ is the curent specification wh foul lags on both $M$ and $G$ and endpoint constraints.
\end{abstract}

3. The test of all four endpoint constraints rejects these constraints for both specifications A and B, but not for the current specification. The head constraint on $\dot{M}$, however, is never rejected by the F-test, and the tail constraint is rejected only for specification B. Nevertheless, in general, the endpoint constraints do not fare well when applied to the longer lag specifications.

\section{Ontotsample Torecast Comparisons}

While it is clear that the altemative PDL representations of the St. Louis equation perform better on an in-sample comparison, it is interesting to see how well they perform on the basis of out-of-sample forecasts. To this end, we estimated these specifications from II/1962 to a terminal period and forecasted out-ofsample for four quarters. We then added four quarters to our estimation period, re-estimated the equation and repeated the process. We did this for six periods beginning with a terminal date of IIJ/1976, generating 24 out-of-sample forecasts of the growth of nominal GNP. The root mean square errors (RMSEs) of these forecasts are summarized in table 4 . Both the $\mathrm{PH}$ specification and the current specification do about equally well by a RMSE criterion over the entire period; there are significant differences, however, in 


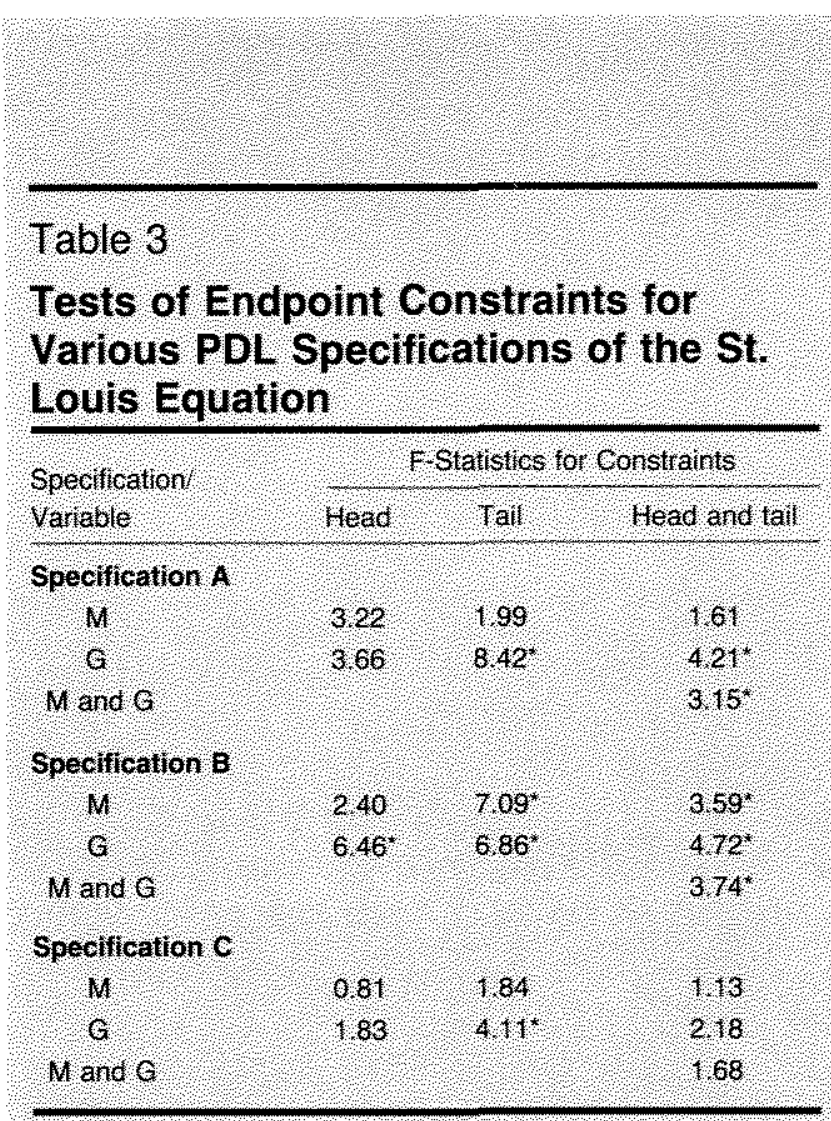

Thdicates significance at the 5 percent evel.

Table 4

\section{Root Mean Square Error of the Forecast for Various Specifications of the St. Louis Equation}

\begin{tabular}{|c|c|c|c|}
\hline Perod & A & $\mathrm{B}$ & $\odot$ \\
\hline $1 \mathrm{~W} 1976-111982$ & 4.77 & 4,49 & 470 \\
\hline V1976 111/977 & 4,3 & 277 & 298 \\
\hline $141977-11 / 9978$ & 342 & 531 & 620 \\
\hline $1 \times 197811 / 1979$ & 5.35 & 381 & 202 \\
\hline $10197911 / 1980$ & 417 & 289 & 417 \\
\hline U/1980-11/1981 & 628 & 596 & 487 \\
\hline W/1981 11/1982 & 472 & 516 & 625 \\
\hline
\end{tabular}

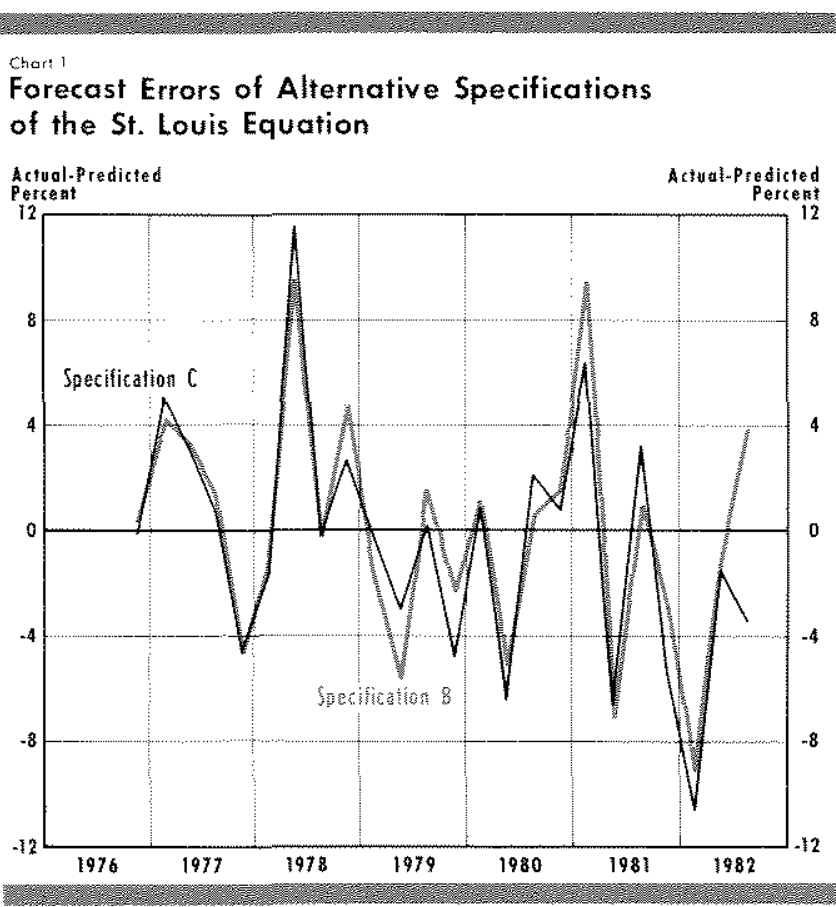

their subperiod forecast performances. ${ }^{28}$ The most restricted PDL specification shows an improvement over the current specification, reducing the out-of-sample RMSE by nearly 5 percent over the period and producing a smaller RMSE of the forecast in four of the six subperiods. A graph of the out-of-sample forecast errors for specifications $B$ and $C$ is presented in chart $I$. It is clear from chart 1 that both specifications produce similar pattems of forecast errors over the period. The only significant exception occurs in the third quarter of 1982 , when specification B underpredicts nominal GNP growth by about as much as specification Coverpredicts it.

\section{GUMMAY AND CONCLUSTONS}

This paper has investigated the lag length and polynomial degree specifications of the St. Louis equa-

\footnotetext{
One could argne that the result may be biased in favor of our PDL specification becanse the lag structure was chosen over the entire period. Indeed, the lag stricture appears to lengthen during the latter part of the sample. The estimated lag structure for the period ending $111 / 1976$ was four on $\dot{M}$ and six on $G$. Thus, the lag structure chosen was nearly that of the current specification. The PDL speciffation was a first degree polynomial on $\dot{M}$ and a sixth degree on $G$. When this specification was used to forecast ont-ofsample, it performed somewhat worse than the current specification, with a RMSE of 4.89 . Our estimates indicate that the lay structure lengtlened when the terminal dite of the sample period was extended to IIV/ 1979 . If the shorter lag structure were used over the first three subperiods and the longer lags structure (specification B) used over the last three, the RMSE for the entire period would be 4.39 , somewhat better than either specification alone.
} 
tion to determine whether its conclusions about the long-run efficacy of monetary policy and inefficacy of fiscal policy are affected by the lag length employed or its polynomial distributed lag specification. In so doing, we have employed a computationally efficient method for determining the appropriate lag length and polynomial degree of a general polynomial distributed lag model.

Our results indicate that the important policy conclusions of the St. Louis equation are insensitive to the lag length specified and to the polynomial restrictions imposed. In particular, the long-run effectiveness of money growth and the long-run ineffectiveness of growth in high-employment government expenditures are substantiated by ordinary least squares estimates of model parameters using both the Pagano-Hartley-

\section{APPENDIX}

Pagano and fHartley have recently developed a methodology for determining the appropriate lag length and degree of polynomial which is computationally efficient. ${ }^{1}$ In order to illustrate the use of the Pagano-Hartley (PH) technique, consider the general distributed lag model

$$
Y_{t}=\sum_{k=1}^{K} \mu_{k} Z_{k t}+\sum_{j=0}^{\ell^{*}} \beta_{j} X_{t-j}+\varepsilon_{t} t=1,2, \ldots, T,
$$

where $\varepsilon_{\mathrm{t}} \sim \operatorname{NID}\left(0, \sigma^{2}\right)$, and where $Z_{k t}$ is the $k^{\text {th }}$ independent variable and $X_{t}$ is an independent variable which affects $Y_{1}$ with a lag of length $\ell^{*}$.

The polynomial distributed lag (PDL) model involves imposing restrictions on the $\beta$ coefficients such that

$$
\beta_{\mathrm{j}}=\delta_{0}+\delta_{1}{ }^{j}+\delta_{2} j^{2}+\ldots+\delta_{\mathrm{p}^{*}} j^{p^{*}}
$$

That is, each of the individual lag weights falls on a polynomial of degree $p^{*}$, where $p^{*}<\ell^{*}$. ${ }^{2}$ These restrictions can be written more compactly in matrix notation as

$$
\beta=H \delta \text {, }
$$

where $\underline{\beta}=\left(\beta_{0} \beta_{1} \ldots \beta_{Q^{*}}\right)^{\prime}, \underline{\delta}=\left(\delta_{0} \delta_{1} \ldots \delta_{\mathrm{p}^{*}}\right)^{\prime}$, and $\mathrm{H}$ is

\footnotetext{
'Pagano and Hartley, "On Fitting Distributed Lag Models."

${ }^{2}$ Strictly speaking, $p^{*}$ could equal $\ell^{*}$; however, there would be no polynomial restrictions. Thus, it is doubtful that one would describe a model as a PDL if $p^{*}=0$
}

determined lag length and the current lag length specifications, as well as by estimates of several PDL specifications. Thus, there is no evidence that the conclusion of the St. Louis equation can be traced to these types of econometric misspecification.

We did find a PDL specification that outperforms the current specification by both in-sample and out-ofsample criteria. This specification has considerably longer lags on both the monetary and expenditure variables and more polynomial restrictions.

Finally, we found that the Pagano-Hartley technique, used in conjunction with standard F-tests, is a convenient and computationally efficient tool for selecting the lag length and polynomial degree of a PDL model. $\mathrm{a}\left(\ell^{*}+1\right)$ by $\left(\mathrm{p}^{*}+1\right)$ matrix of coefficients. ${ }^{3}$ Substituting the above restrictions into the model, we get

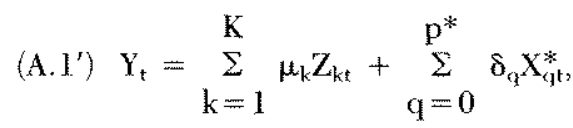

$x$

where $X_{q t}^{*}=\sum_{j=0}\left(X_{i-j} h_{j+1}, q_{i}+1\right)$ and where $h_{j+1, q+1}$ is the $(j+1) t h,(q+1)$ th element of $H, j=0,1,2, \ldots \ell^{*}$ and $q=0,1,2, \ldots, p^{*}$. It is clear that imposing the polynomial restrictions reduces the number of parameters by $\ell^{*}-p^{*}$ and, thus, imposes $\ell^{*}-p^{*}$ homogeneous restrictions on the parameter vector $\beta$. Thus, estimating equation $A . I^{\prime}$ is tantamount to estimating equation A.l subject to homogeneous restrictions of the form $R \beta=0$, where $R$ is $a\left(\ell^{*}-p^{*}\right)$ by $\left(\ell^{*}+1\right)$ matrix. ${ }^{4}$ It should be apparent that the validity of the

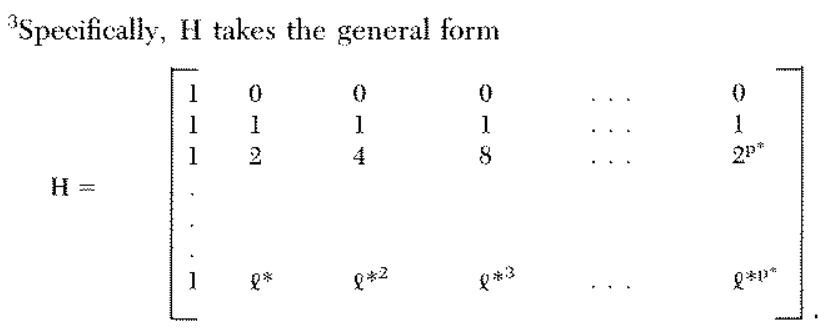

${ }^{2}$ There are a number of ways of generating the restriction matrix, $R$. See Shiller, "A Distributed Lag Estimator;" and J udge and others, The Theory and Practice of Econometrics (John Wiley and Sons, Inc., 1980), pp. 642 44 . 
polynomial restrictions, including the endpoint constraints, can be tested easily. ${ }^{5}$

Of course, the correct values of the lag length and degree of the polynomial are generally unknown. Since the selection of an improper lag length or polynom mial degree generally leads to biased coefficient estimates, the selection of $\ell$ and $\mathrm{p}$ is extremely important. The selection process, however, is not easy. For one thing, the appropriate lag length cannot be determined using standard procedures if the degree of the polynomial has been selected ${ }^{6}$ Even though a number of techniques have been suggested for selecting $\ell$ and $\mathrm{p}$, the PH method was chosen, in part for its computational convenience. ${ }^{7}$

The PH method proceeds by determining the lag length and then the degree of the polynomial. The PH technique can best be illustrated by rewriting equation A.1 in matrix form as

$$
\underline{Y}=Z_{\underline{\mu}}+X \underline{\beta}+\underline{\varepsilon}
$$

where $Z$ and $X$ are $T$ by $K$ and $T$ by $\left(\ell^{*}+1\right)$ matrices of observations on the independent variables, and $\mu$ and $\beta$ are $K$ by 1 and $\left(\ell^{*}+1\right)$ by 1 vectors of parameters. The procedure begins by choosing a maximum lag length L. Equation A. 2 with the maximum lag length can be rewritten as

(A.3) $\underline{Y}_{\mathrm{L}}=W_{\mathrm{L}} \underline{\psi}_{\mathrm{i}}+\underline{\varepsilon}_{\mathrm{L}}$

where $W_{L}=\left[Z: X_{L}\right]$, and $\psi_{\mathrm{L}}=\left[\mu: \beta_{\mathrm{L}}\right]^{\prime}$. The observation matrix $W_{\mathrm{L}}$ is then decomposed to

\footnotetext{
${ }^{5}$ There are a number of alternative norms for testing these restrictions. See Judge and others, The Theory and Practice of Econometrics, p. 646

"This is seen by noting that, once the polynonial degree is selected, alternative lag specifications amount to imposing the polynomial restrictions on different parameter spaces. Thas, restrictions on the lag length are non-nested when $p$ is specified. See Peter Schmidt, "A Modification of the Almon Distributed Lag," Journal of the American Statistical Association (September 1974), pp. 679 81; and Hendry and Pagan, "Distributed Lags: A Survey of Some Recent Developments." In this regart, it would be appropriate to use the maximum $\overline{\mathrm{R}}^{2}$ criterion as Schmidt and Waud do; however. this procedure may lack power. A more useful procedure has been suggested by Pesaran. Neither procedure, however, provides information concerning the degree of polynomial. See Schmidt and Waud, "The Almon Lag Technique"; and M. H. Pesaran, "On the General Problem of Model Selection," Review of Economic Studies (Aptil 1974), pp. 153-71.

TOne attractive method has been suggested by Hendry and Pagan, "Distributed Lags: A Survey of Some Recent Developments." This procedure involves a sequence of hypothesis tests commencing with an initial arbitrary choice of a lag length. While this procedure has potential merit, it is not without its difficulties. Furthermore, it may involve an extremely laborious test procedure when there are two PDL variables, as in the St. Louis equation. For another procedure, see Sargan, "The Consumer Price Equation in the Post War British Economy."
}

$$
W_{\mathrm{L}}=Q_{\mathrm{L}} \mathrm{N}_{\mathrm{L}}
$$

by the Gram-Schmidt decomposition. Here $\mathrm{Q}_{\mathrm{L}}$ is a matrix whose columns form an orthonormal basis for the column space of $\mathrm{W}_{\mathrm{L}}$, and $\mathrm{N}_{\mathrm{L}}$ is an upper triangular matrix with positive diagonal elements. ${ }^{8}$ Equation A.3 now can be rewritten as

$$
\underline{Y}_{\mathrm{L}}=Q_{\mathrm{L}} \underline{\lambda}_{\mathrm{L}}+\underline{\varepsilon}_{\mathrm{L}}
$$

where

$$
\underline{\lambda}_{\mathrm{L}}=\left[\underline{\lambda}^{\mu}: \underline{\lambda}_{\mathrm{L}}^{\beta}\right]^{\prime}=\mathrm{N}_{\mathrm{L}} \underline{\psi}_{\mathrm{L}}
$$

Given that $Q_{\mathrm{L}}$ is orthonomal, the least squares estimate of $\lambda_{\mathrm{L}}$ is given by

$$
\hat{\underline{x}}_{\mathrm{L}}=\left[\hat{\hat{\Lambda}}^{\mu} \cdot \hat{\hat{\lambda}}_{\mathrm{L}}^{\beta_{\mathrm{B}}}\right]^{\prime}=\mathrm{Q}_{\mathrm{L}}{ }^{\prime} \underline{\mathrm{Y}}_{\mathrm{L}}
$$

and the structural parameters can be obtained from

$$
\mathrm{N}_{\mathrm{L}} \underline{\underline{\psi}}_{\mathrm{L}}=\underline{\hat{\lambda}}_{\mathrm{L}}
$$

An advantage of the $\mathrm{PH}$ method comes in noting that the elements of $\hat{\lambda}_{\mathrm{L}}$ are mutually independent random variables. In particular,

$$
\begin{aligned}
& \hat{\lambda}_{i}^{\beta} \sim \operatorname{NID}\left(\lambda_{i}, \sigma^{2}\right), i=0,1,2, \ldots, e^{*} \\
& \hat{\lambda}_{i}^{\beta} \sim \operatorname{NID}\left(0, \sigma^{2}\right), i=e^{*}+1, \ell^{*}+2, \ldots, L .
\end{aligned}
$$

Pagano and Hartley note that there is a one-to-one correspondence between the null hypothesis involving the $\beta s$ and the $\lambda s$. Given this and the orthogonality of the $\mathrm{PH}$ procedure, the following sets of hypotheses are equivalent:

$$
\begin{aligned}
\mathrm{H}_{\mathrm{L}-\mathrm{j}}: \beta_{\mathrm{L}}=\beta_{\mathrm{L}-1}=\ldots=\beta_{\mathrm{L},-\mathrm{j}}=0 \\
\mathrm{j}=0,1,2, \ldots, \mathrm{L} \\
\mathrm{H}_{\mathrm{L}-\mathrm{j}}^{*}: \lambda_{\mathrm{L}}^{\beta}=\lambda_{\mathrm{L}-1}^{\beta}=\ldots=\lambda_{\mathrm{L}, j}^{\beta}=0 \\
\mathrm{j}=0,1,2, \ldots, \mathrm{L} .
\end{aligned}
$$

Hence, the Gram-Schmidt decomposition provides a convenient basis for testing the null hypothesis that there exists a lag length, $\ell$, such that the null hypothesis $\beta_{\ell}=0$ can be rejected. If no such $\ell$ can be found, then there is no distributed lag of X.

The test of the simple hypothesis $\lambda_{\mathrm{L}-\mathrm{j}}^{\beta}=0$ can be carried out by a t-test of the form

$$
\mathrm{t}_{\mathrm{I},-j}=\lambda_{\mathrm{L}-\mathrm{j}}^{\mathrm{B}} / \mathrm{s} \quad \mathrm{j}=0,1,2, \ldots, \mathrm{L},
$$

where

$$
\begin{aligned}
& \mathrm{s}^{2}=\frac{\mathrm{e}_{\mathrm{L}}{ }^{\prime} \underline{\mathrm{e}}_{\mathrm{L}}}{\mathrm{T}-\mathrm{K}-\mathrm{L}-1}, \text { and } \\
& \underline{\mathrm{e}}_{\mathrm{L}}=\underline{\mathrm{Y}}_{\mathrm{L}}-\mathrm{Q}_{\mathrm{L}} \hat{\hat{\lambda}}_{\mathrm{L}} .
\end{aligned}
$$

${ }^{*}$ The Gram-Schmidt procedure is often used when the observation matrix is ill-conditioned. If the diagonal elements are chosen to be positive, as they are in our case, $Q_{L}$ and $N_{L}$ are unique; see $C . A$. Seber, Linear Regression Analysis (Jom Wiley and Sons, Inc., 1977), chapter 11 . 
Because of their common divisor, these t-statistics are not independent; however, they are uncorrelated. ${ }^{9}$

Pagano and Hartley also suggest that the above hypotheses are equivalent to

$$
\mathbf{H}^{\prime}{ }_{\mathrm{L}, j}, \lambda_{\mathrm{L},-\mathrm{j}}^{\beta}=0 \quad \mathrm{j}=0,1, \ldots, \mathrm{L},
$$

due to the orthogonality of their procedure. These hypotheses, however, are not equivalent in any direct sense. To see this, recall that

$$
\underline{\lambda}_{\mathrm{L}}=\mathbf{N}_{\mathrm{L}} \Psi_{\mathrm{L}}
$$

where $\mathrm{N}_{\mathrm{L}}$ is an upper-triangular matrix with positive diagonal elements. The ith row of $\mathrm{N}_{\mathrm{L}}$ can be represented as

$$
\mathrm{N}_{\mathrm{L}}^{\mathrm{i}}=\left(0, \ldots, 0, \eta_{\mathrm{ii}}, \eta_{\mathrm{ii}+1}, \ldots, \eta_{\mathrm{iL}}\right)
$$

where $\eta_{i j}$ is the ith-jth element of $N_{L}$. Thus, the hypothesis test that $\lambda_{L}^{\beta}=0$ is given by

$$
\lambda_{\mathrm{L}}^{\beta}=\eta_{\mathrm{L}} \beta_{\mathrm{L}}=0 \text {. }
$$

Likewise, the test that $\lambda_{\mathrm{L}-1}^{\beta}=0$ is given by

$$
\lambda_{\mathrm{L}-1}^{\beta}=\eta_{\mathrm{L}-1} \beta_{\mathrm{L}-1}+\eta_{\mathrm{L}} \beta_{\mathrm{L}}=0,
$$

and so on. Thus, the hypotheses of $\mathrm{H}^{\prime}{ }_{\mathrm{L}-\mathrm{j}}$ are really tests of linear combinations of the distributed lag weights, where the particular linear combination is determined by the elements of rows of $N_{L}$. In practice we found that the absolute value of the diagonal elements of $\mathrm{N}_{\mathrm{L}}$ tended to be somewhat large relative to the off-diagonal elements for the lag length selection and very small relative to the off-diagonal elements in the polynomial selection. In the former case, therefore, testing the hypothesis that $\lambda_{j}^{\beta}=0$ was very near testing the hypothesis that $\beta_{j}=0$, while in the later case it was closer to the null hypothesis $H_{\mathrm{L}-\mathrm{j}}^{*}$.

Given this, we decided to supplement the use of t-tests on the $\lambda s$ with conventional $F$-tests of the equivalent hypotheses of $\mathrm{H}$ and $\mathrm{H}^{*}$. We recommend that one investigate the $\mathrm{N}_{\mathrm{L}}$ matrix to identify the nature of the hypotheses being tested when using the $\mathrm{PH}$ t-statistics.

We should note also that the use of the PH method is complicated somewhat by the presence of two distributed lag variables on the right-hand side. One can readily see that, in view of the upper-triangular form of $\mathrm{N}_{\mathrm{L}}$, hypothesis tests involving a second distributed lag will not be consistent with $\mathrm{H}_{\mathrm{i}-\mathrm{j}}^{*}$ unless the GramSchmidt procedure is applied to each set of distributed lag regressors separately. Unfortunately, the resulting

\footnotetext{
This permits the use of t-tables from Seber. See Seber, Linear Regression Analysis, pp. $404-5$.
}

sets of jointly orthogonal regressors will not themselves be orthogonal to each other. As an alternative, we ran two separate Gram-Schmidt regressions with each distributed lag variable entered last. Furthermore, we did this by reducing by one the lag length or polynomial degree for one variable and holding the maximum lag length or polynomial degree for the other variable (which was entered last) constant. In this way, we determined whether the lag length chosen for one variable was affected by the lag length specified for the other. Of course, we were particularly concerned that the lag length selected for one be the same if the chosen lag length of the other was used instead of $L$. The procedure had the added advantage of allowing us to calculate an $\mathrm{L}$ by $\mathrm{L}$ matrix of $\mathrm{F}$-statistics for all possible combinations of lag structures (or in the case of PDL selection, degrees of polynomials) from $L$ orthogonal regressions. ${ }^{10}$

\section{IXypothesis Testing Considerations}

When determining the "correct" lag length using either the t-tests or the F-test, care must be taken in choosing a critical value on which to test the null hypothesis. Two considerations are important. First, the null hypotheses

$$
\mathrm{H}_{\mathrm{L}-\mathrm{j}}^{*} \lambda_{\mathrm{L}-\mathrm{j}}^{\beta_{-}}=0 \quad \mathrm{j}=0,1,2, \ldots, \mathrm{L}
$$

represent a set of sequential hypotheses. It is usually assumed that these hypotheses are nested so that if any one is true, the preceding hypotheses must be true also and, if any one is false, so must be the succeeding ones. Thus, the null hypothesis becomes more restricted as each successive test is conducted, and the probability of committing a Type $I$ error increases. If we let $\zeta_{\xi}$ denote the significance level of the $j$ th test, it can be shown that the probability of committing a Type I error for the $j$ th test, $\alpha_{j}$, is

$$
\alpha_{j}= \begin{cases}\zeta_{1} & \text { if } j=1 \\ \zeta_{j}\left(1-\alpha_{j \ldots 1}\right)+\alpha_{j-1} & \text { if } j \geqslant 2\end{cases}
$$

Thus, the probability of rejecting the null hypothesis when it is true will rise as the length of the lag is reduced. Anderson suggested that one would like to balance the desirability of not overestimating the lag length with the sensitivity to non-zero coefficients. ${ }^{11}$ He recommends setting $L$ fairly large, but letting $\zeta_{j}$ be

\footnotetext{
10 This can be seen by noting that the $\mathrm{RSS}$ when $\mathrm{j}$ lags are omitted is given by

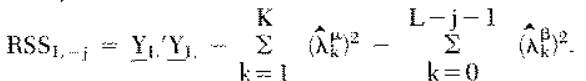

"Anderson aso provdes a test procedure for orthogodal regressors which have some optimal properties; lowever, the test is somewhat cumbersone. See $T$. W. Anderson, The Statistical Analysis of Time Series (John Wiley and Sons, Jne, 1971), pp. 30-43.
} 
small for j near L. While no optimal rules exist, Anderson suggests

(A.4) $\zeta_{\mathrm{j}}=\frac{\zeta \mathrm{L}+1-\mathrm{j})}{\mathrm{L}} \mathrm{j}=1,2,3, \ldots, \mathrm{L}$

for subsequent tests. An alternative would be to use the t-tables from Seber.

In addition to the above problem, we have the problem that an estimator based on a prior test is a preliminary test estimator. While nothing is known about such estimators when the sequence of tests is greater than one, it is known that, in the case of one pre-test, the estimator has a risk function which may exceed that of OLS. ${ }^{12}$ Furthermore, the difference between the risk of the preliminary test estimator and OLS increases as the significance level is reduced. While the optimal critical value will vary with the particular choice of loss function, the evidence suggests that standard significance levels of 5 or 10 percent may be below the optimal level for one pre-test. ${ }^{13}$ These considerations, coupled with the fact that overestimates of the lag length are less likely to result in bias than underestimates, suggest that one may want to consider an initial value of the significance level that is fairly large. ${ }^{\mathrm{I}-4}$

\section{POL WOMTAL DEGRE SELECTON}

Having selected a lag length, $\ell$, the next step is to determine a polynomial degree, $\mathrm{p}$. This can be accom-

\footnotetext{
${ }^{12}$ The risk function is $\left.\mathrm{E}\left[\varphi^{*}-\varphi\right)^{\prime} \mathrm{X}^{\prime} \mathrm{X}\left(\varphi^{*}-\varphi\right)\right]$, where $\varphi^{*}$ is the pretest estimator of $\varphi$.

${ }^{13}$ For example, sawa and Hiromatsu have shown that the standard critical values of the t-statistic are substantially above the optimal critical values in the case of a mini-nax regret loss function with one restriction. On the other hand. Toyoda and Wallace have shown that OLS should always be chosen when the number of linearly independent restrictions are less than five if one wishes to minimize the average regret. See Takanitst Sawa and Takeshi Ifiromatsu, "Mininax Regret Significance Points for a Prefininary Test in Regression Analysis," fconomefrica (November 1973), pp. 1093-1101; and T. Toyoda and T. D. Wallace, "Optinal Critical Values for Pre-Testing in Regression," Econometrica (March 1976), pp. 365-75.

"To guard against meorrectly excluding components of the distrib. thed lag or imposing invalid polynomial restrictions, an initial significance level of 15 percent was chosen. The critical t-values for testing each stccessive bypothesis are as follows:
}

\begin{tabular}{cc}
$\frac{j}{1}$ & t-value \\
\cline { 2 - 2 } 2 & 1.46 \\
2 & 1.51 \\
3 & 1.56 \\
4 & 1.61 \\
5 & 1.67 \\
6 & 1.74 \\
7 & 1.81 \\
8 & 1.99 \\
9 & 2.00 \\
10 & 2.12 \\
11 & 2.30 \\
12 & 2.57
\end{tabular}

plished by simply re-applying all of the procedures outlined above to the PDL model with lag length $\ell$. To see this, write the model with the selected lag length as

$$
\underline{Y}_{\ell}=Z_{\underline{\mu}}+\mathrm{X}_{\ell} \underline{B}_{\ell}+\varepsilon_{\ell}
$$

Recall that $\beta=H \delta$ where $H$ is $(\ell+1)$ by $\left(p^{*}+1\right)$ and $\delta$ is $\left(\mathrm{p}^{*}+1\right)$ by 1 . Thus, this equation can be rewritten as

(A.6) $\underline{Y}_{\ell}=Z_{\underline{\mu}}+\mathrm{X}_{\ell} \mathrm{H} \delta+\underline{\varepsilon}_{\ell}$

Or

(A.6. $\underline{Y}^{*}=Z \underline{\mu}=X^{*} \underline{\delta}+\underline{\varepsilon}^{*}$.

It is clear from this expression that the choice of a polynomial degree $p$ is completely analogous to the choice of the lag length above, where the maximum degree of the polynomial considered, $\mathrm{p}$, initially is set equal to $\ell^{15}$

\section{EMPIRICA RESULTS}

In applying the $\mathrm{PH}$ technique, we initially chose a maximum lag length of 12 ; however, we also considered $L=16$. The PII t-statistics for those runs with both $\dot{M}$ and $\dot{G}$ last are given in table A. 1 . This procedure chose 10 lags on $\dot{M}$ and 9 on $\dot{G}$ for $L=12$ and 16 . We then chose these lags for one variable and let the other be set at $L=12$. The results were unchanged. These results also appear in table A. 1 . Furthermore, F-tests of the restrictions implied by this section were basically consistent with the $\mathrm{PH}$ results, when $\mathrm{L}$ was set at 12 (see footnote 24 of the text). This was not trie, however, for $L=16$. In this instance, the presence of a number of insignificant coefficients prior to the first significant one diluted the calculated $\mathbf{F}$-statistic so that a very short lag would have been chosen by an F-test. Thus, the PH t-statistics appear to be less sensitive to the choice of $L$ than the standard F-test.

Letting the maximum degree polynomial be 10 for $\dot{\mathrm{M}}$ and 9 for $\dot{\mathrm{G}}$, we then re-applied the PH technique to

\footnotetext{
${ }^{15}$ Pagano and Hartey offer an equivalent two step procedıre. which is not discussed here See Pagano and Hartley, "On Fitting Distributed Lag Models Subject to Polynomial Restrictions." As ar efficient alternative to ether of these approaches, one could employ the stochastic information from the lag length selection process with the nonstochastic information in the design matrix in a Theil-Coldberger nixed estimation procedure similar to Schil ler's Bayesian method. Fomby has shown that such stochastic restrictions can be tested under a generalized mean square error norm. See II. Theil and A. S. Goldberger, "On Pure and Mixed Statistical Estimation in Eeonomics," International Economic Review (January 196I), pp, 65-78; Thomas B. Fomby, "MSE Evaltation of Shiller's Smoothness Priors," International Economic Reciow (Febrtary 1979), pp. 203-15; and julge and others, The Theory and Practice of Econometrics, pp. $652-53$.
} 
Table A.1

Pagano-Hartley t-statistics for Lag Length Selection

\begin{tabular}{ll}
\hline \\
\hline
\end{tabular}

First signitcant t statistic

Table A.2

\section{Pagano-Hartley $t$-statistics for Polynomial Degree Selection}

\begin{tabular}{|c|c|c|}
\hline Polyorral & or & on \\
\hline 0 & 344 & 0027 \\
\hline 1 & 378 & 28 \\
\hline 2 & 204 & $\$ 0.17$ \\
\hline 3 & 2,17 & 2277 \\
\hline 4 & 2234 & 0,73 \\
\hline 5 & 048 & 105 \\
\hline 6 & 2230 & 112 \\
\hline 7 & 044 & 280 \\
\hline 8 & ४ै। & $3,65 \%$ \\
\hline 9 & ?ै185 & 0.47 \\
\hline 10 & 126 & \\
\hline
\end{tabular}

Tirst significant t staisstic

determine the polynomial degree. The PH t-statistics are presented in table A.2. The PH technique selected a ninth degree polynomial on money and an eighth degree polynomial on government expenditures for the same significance level as used before. When we re-estimated the equation on the lower degree polyno- mials, however, the coefficient of the eighth degree on $\dot{\mathrm{G}}$ failed to be significant. The seventh was significant, regardless of the lag length on $\dot{M}$. Thus, the PH technique suggests a ninth degree polynomial on $\dot{M}$ and a seventh degree on $\dot{G}$. This implies only one polynomial restriction on $\dot{\mathrm{M}}$ and two on $\dot{\mathrm{G}}$. (An F-test of these restrictions could not reject the null hypothesis. The calculated $\mathrm{F}$-statistic was 1.43.)

Furthermore, the matrix of $F$-statistics of all possible polynomial restrictions on a PDL model with 10 lags on $\dot{M}$ and 9 on $\dot{G}$, given in table $A .3$, suggests that even more restricted models could pass an F-test. Clearly, a number of different polynomial degree specifications satisfy an $F$ utest at the 5 percent level. We can see, for example, that had we chosen the polynomial degree on $\dot{\mathrm{M}}$ first and then selected the polvnomial degree on $\dot{\mathrm{G}}$, we would have chosen a fourth degree polynomial on $\dot{\mathrm{M}}$ and an eighth degree polynomial on $\dot{\mathrm{G}}$.

Alternatively, had we investigated $\dot{G}$ first, we would have chosen a seventh degree polynomial on $\dot{\mathrm{C}}$ and a sixth on $\dot{M}$. These are circled in table A.3. We could also choose the polynomial degree by selecting the most restricted model that passes an F-test at, say, the 5 percent level. This criterion would select a sixth degree polynomial on $\dot{M}$ and a third degree on $\dot{G}$. This F-statistic is bracketed in table A.3. All four of these 


\section{Table A.3}

\section{F-statistics for Testing Polynomial Restrictions on $\bar{M}$ and $\dot{G}$}

\begin{tabular}{|c|c|c|c|c|c|c|c|c|c|c|}
\hline Degrees for $\mathrm{M}$ & & & & & Degr & 10 & & & & \\
\hline & 0 & 1 & 12 & 8 & 4 & 5 & 6 & 7 & 8 & 9 \\
\hline 0 & 4.09 & 4.3 & 438 & 4.53 & 475 & 508 & 5.47 & $5: 62$ & 576 & 6.92 \\
\hline 1 & 3.00 & 2.64 & 280 & 282 & 292 & 3.10 & 3.32 & 320 & 305 & 3.37 \\
\hline 2 & 2,78 & 2.46 & 2.61 & 250 & 2.65 & 270 & 299 & 287 & 250 & 279 \\
\hline 3 & 280 & 246 & 263 & 254 & 257 & 264 & 282 & 268 & 2.24 & 251 \\
\hline 4 & 249 & 2,3 & 2.30 & 210 & 2.21 & 2.26 & 243 & 2,13 & $(7,76)$ & 202 \\
\hline 5 & 261 & 226 & 2.45 & 228 & 2.41 & 2.49 & 269 & 240 & 2.02 & 237 \\
\hline 6 & 258 & 2.17 & 237 & (1, 961 & 2,10 & 221 & 237 & $(1,46)$ & 133 & 1,62 \\
\hline 7 & $2.7 ?$ & 235 & 2.59 & 214 & 283 & 251 & 277 & 174 & 1.63 & 209 \\
\hline 8 & 302 & 256 & 2.84 & 227 & 2.54 & 268 & 620 & 182 & 176 & 2.52 \\
\hline 9 & 303 & 2.48 & 279 & 209 & 287 & 266 & 294 & 143 & 087 & 1,60 \\
\hline 10 & 0.13 & 2.51 & 2.86 & 206 & 237 & 269 & 3.16 & 1.48 & 022 & $=$ \\
\hline
\end{tabular}

PDL specifications - the one selected by the PH technique and the three indicated in table A.3 - were estimated; however, only the results for the one selected by the PH technique and the most restricted specification are presented in this paper. The results of the other specifications were similar to those of the most restricted PDL specification and, hence, are not reported here. ${ }^{16}$

\footnotetext{
${ }^{16}$ The hypothesis tests concerning the effects of monetary and fiscal policy yielded conclusions identical to those reported here. The out-of-sample RMSEs of the forecast for the period III/1976-IIU 1982 were smaller than the RMSEs of specifications $A$ or $C$.
}

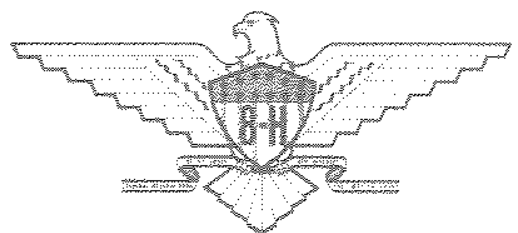

